American Journal of Agricultural and Biological Sciences 5 (3): 415-421, 2010

ISSN 1557-4989

(C) 2010 Science Publications

\title{
Use of Quantitative Polymerase Chain Reaction for Determining Copy Numbers of Transgenes in Lesquerella fendleri
}

\author{
Grace Qianhong Chen and Jiann-Tsyh Lin \\ Department of Agriculture, Western Regional Research Center, \\ Agricultural Research Service, 800 Buchanan St., Albany, CA 95710, USA
}

\begin{abstract}
Problem statement: In transgenic plants, the number of transgene copies could greatly influence the level of expression and genetic stability of the target gene, thus it is important to develop an efficient method for accurate estimation of transgene copies. The quantitative Polymerase Chain Reaction (qPCR) technique is becoming more efficient nowadays to determine copy numbers of transgenes in transgenic plants, being used here, for the first time in quantifying copy numbers of transgenes in Lesquerella fendleri. Approach: The system utilized a known one copy gene, LfKCS4/5, from L. fendleri as an endogenous calibrator and the threshold Crossing point $(\mathrm{Ct})$ measured by Applied Biosystem 7500 system to calculate the copy numbers of transgenes in primary transgenic lines (T0 generation). Results: The qPCR condition was optimized and each primer set had a PCR efficiency of 0.99 or 1.01. Our data demonstrated unambiguous 2-fold discrimination of the copy number of B-glucuronidase gene (gusA) and hygromycine phosphotransferase II (hptII) genes in 12 T0 lines. Most of the lines contained one or two copies of each gene. Eight out of 12 samples (66.7\%) showed more copies of gusA gene than that of hptII gene, suggesting rearrangements of the Transferred (T)-DNA. Possible modifications of the T-DNA cassette in L. fendleri are discussed based on main models of T-DNA integration in the plant genome. Conclusion: The qPCR described in this study is an efficient method and it is particularly useful in identification and selection of transgenic plants with desirable copy numbers at early stage.
\end{abstract}

Key words: Lesquerella fendleri, quantitative PCR, polymerase chain reaction, transgenes

\section{INTRODUCTION}

Lesquerella fendleri (A. Gray) S. Wats. (Brassicaceae), under development as a new industrial oilseed crop in the southwestern region of US, is valued for its unusual Hydroxy Fatty Acid (HFA). HFAs and derivatives are used as raw materials for numerous industrial products, such as lubricants, plasticizers and surfactants (Caupin, 1997).

Considerable efforts have been made to improve the productivity of $L$. fendleri through plant breeding (Dierig et al., 2006; 2004; Isbell et al., 2008). Because L. fendleri is amenable to Agrobacterium-mediated transformation (Skarjinskaia et al., 2003; Wang et al., 2008), alternative means to improve this crop exist through genetic engineering. When new transgenic plants are obtained, one essential step is to determine the copy number in the transgenic plants, because the copy number can greatly influence the expression level and genetic stability of the target gene. The number of transgene copies has traditionally been estimated by Southern analysis, in which a blot of digested genomic DNA is hybridized with a radioactive DNA probe corresponding to the transgene to produce an informative band pattern. The drawbacks of this method are laborious and time-consuming, especially when a large number of samples need to be estimated (Ingham et al., 2001). It requires a great amount of DNA and hazardous radio-isotopes (Mason et al., 2002). Moreover, Southern analysis often underestimates transgene copies when two copies of transgenes are inserted into one locus, because the digested DNA fragments containing each gene are very similar in size and thus indistinguishable by Southern analysis (Mason et al., 2002).

Recently, the development of quantitative Polymerase Chain Reaction (qPCR) methods for determining the transgene copy number has overcome the limitations of Southern analysis (Ingham et al., 2001; Mason et al., 2002). To date, qPCR technology

Corresponding Author: Grace Qianhong Chen, Department of Agriculture, Western Regional Research Center, Agricultural Research Service, 800 Buchanan St., Albany, CA 95710, USA

Tel: 510-559-5627 Fax: 510-559-5999 
has been applied to analyze copy number of transgenic plants, including soybean and peanut (Schmidt and Parrott, 2001), tomato (Mason et al., 2002), maize (Ingham et al., 2001; Shou et al., 2004; Song et al., 2002), rapeseed (Weng et al., 2004), wheat (Doshi et al., 2007; Li et al., 2004), rice (Jiang et al., 2009; Yang et al., 2005), tobacco (Subr et al., 2006), cotton (Yi et al., 2008), citrus (Omar et al., 2008), grape (Costa et al., 2009) and cassava (Beltran et al., 2009). To speed up the molecular analysis of transgenic plants, we describe here the development and application of a qPCR method that utilizes an endogenous calibrator and the threshold crossing point $(\mathrm{Ct})$ calculated by the Applied Biosystem 7500 system for determination of transgene copy numbers in L. fendleri. The method presented is rapid, sensitive, robust and easy to optimize.

\section{MATERIALS AND METHODS}

Plant material, bacterial strain: The L. fendleri seeds, WCL-LY2 (Dierig et al., 2001), were kindly provided by Dr. Dave Dierig (USDA-ARS, Arid-Land Agricultural Research Center, Maricopa, AZ). Plants were grown in a greenhouse at temperatures between $28^{\circ} \mathrm{C}$ (day) and $18^{\circ} \mathrm{C}$ (night), with supplemental metal halide lighting to provide a $15 \mathrm{~h}$ day length (1000$1250 \mu \mathrm{mol} \mathrm{m} \mathrm{mec}^{-1}$ ). Mature female flowers were hand-pollinated and the seeds were harvested at about 49 days after pollination. An Agrobacterium tumefaciens strain AGL1 (Lazo et al., 1991) carrying binary vector $\quad$ pCAMBIA 1301.1 (http://www.cambia.org), which contains gusA as a reporter gene and hygromycine phosphotransferase II (hptII) as a selection marker gene was used for plant transformation. An AGL1/pCAMBIA1301.1 culture was started with the inoculation of one clone in $1 \mathrm{~mL}$ Luria Broth (LB, $10 \mathrm{~g} \mathrm{~L}^{-1}$ tryptone, $5 \mathrm{~g} \mathrm{~L}^{-1}$ yeast extract, $5 \mathrm{~g} \mathrm{~L}^{-1}$ sodium chloride, $1 \mathrm{~g} \mathrm{~L}^{-1}$ glucose, $\mathrm{pH} 7$ ) supplemented with $50 \mathrm{mg} \mathrm{L}^{-1}$ kanamycin and $100 \mathrm{mg}$ $\mathrm{L}^{-1}$ carbenicillin shaken at $200 \mathrm{rpm}$ overnight at $29^{\circ} \mathrm{C}$, followed by sub-culturing of $0.1 \mathrm{~mL}$ of the overnight culture in $50 \mathrm{~mL}$ fresh $\mathrm{LB}$ for $24 \mathrm{~h}$.

Tissue culture, transformation and regeneration: Agrobacterium cultures were centrifuged at 4,000 rpm for $10 \mathrm{~min}$ at room temperature $\left(25^{\circ} \mathrm{C}\right)$ and the pellet was suspended to an $\mathrm{OD}_{600}$ of 0.5 in half strength Murashige and Skoog (MS) liquid medium (Murashige and Skoog, 1962). L. fendleri seeds were surfacesterilized in a $0.25 \%(\mathrm{v} / \mathrm{v})$ sodium hypochlorite solution for $15 \mathrm{~min}$ followed by five rinses in sterile deionized water. The seeds were germinated and grown aseptically on Germination Medium (GM) containing half strength of MS medium supplemented with $0.5 \%$ sucrose and $0.6 \%$ agar in a growth chamber at day/night cycle $\left(16 / 8 \mathrm{~h}, 100 \mu \mathrm{mol} . \mathrm{m}^{-2} \cdot \mathrm{s}^{-1}\right)$ at $24^{\circ} \mathrm{C}$ (day) and $22^{\circ} \mathrm{C}$ (night). After 4-6 weeks, shoot tips together with 4-5 true leaves were sub-cultured and grown aseptically on GM for a continuous supply of leaf material.

To perform the transformation, leaves were harvested from plants after 4-6 weeks of sub-culturing and wounded by scratching slightly on the underside of leaf and then dipped in the half strength MS medium containing AGL1/pCAMBIA1301.1 for $5 \mathrm{~min}$. Following the inoculation, leaves were blotted on sterilized filter paper and transferred to Callus and Shoot Induction (CSI) medium composed of Basal Medium (BM, half strength MS medium plus $30 \mathrm{~g} \mathrm{~L}^{-1}$ sucrose and $6 \mathrm{~g} \mathrm{~L}^{-1}$ agar, $\mathrm{pH}$ 5.7) supplemented with 1 $\mathrm{mg} \quad \mathrm{L}^{-1} \quad 6$ Benzylaminopurine (BA) and $0.1 \mathrm{mg}$ $\mathrm{L}^{-1}$ Naphthaleneacetic Acid (NAA). After incubating the infected leaves in the growth chamber for 2 days, the leaves were cut into $5 \mathrm{~mm}$ segments and cultured on Callus/Shoot Induction (CSI) media plus $25 \mathrm{mg} \mathrm{L}^{-1}$ hygromycin (hyg) for transgenic selection and $100 \mathrm{mg} \mathrm{L}^{-1}$ timentin for inhibiting the Agrobaterium growth. In 6-8 weeks, yellow-greenish hygromycin resistant $\left(\right.$ hyg $\left.^{\mathrm{R}}\right)$ calli started to appear on the leaf segments. The calli were than transferred to a timentin-free subculture medium CSI+ (CSI with hyg increased to $50 \mathrm{mg} \mathrm{L}^{-1}$ ). Green shoots were developed from the calli on CSI+ medium in about 2-4 weeks after the transfer.

To eliminate chimeras, each shoot was cut into small pieces (about $1 \times 1 \mathrm{~mm}$ ) and placed on the CSI+ medium for shoot-regeneration. After 4 rounds of successive regenerations, shoots were sub-cultured on $\mathrm{BM}$ plus $1 \mathrm{mg} \mathrm{L}^{-1} \mathrm{BA}, 1 \mathrm{mg} \mathrm{L}^{-1}$ Indole-3-Butyric Acid (IBA) and $50 \mathrm{mg} \mathrm{L}^{-1}$ hyg for multiplication. Shoots $10-15 \mathrm{~mm}$ in length were transferred to rooting medium (BM plus $1 \mathrm{mg} \mathrm{L}^{-1}$ IBA and $50 \mathrm{mg} \mathrm{L}^{-1}$ hyg). When a shoot developed 2-3 roots (usually in 3-5 weeks), it was than transferred to a Magenta box (Sigma, St. Louis, Mo) containing sterilized peatvermiculite growth mixture (Sunshine mix \#4, Planet Natural, Bozeman, MT) pre-soaked with $1 \mathrm{mg} \mathrm{L}^{-1}$ IBA water solution. After 8-10 weeks in the growth mixture, a well-developed primary plant (T0 generation) showing 8-12 normal leaves and 2-3 inch height was transferred to a 6-inch pot and placed under a transparent plastic cover for the first 2 weeks for acclimation in the greenhouse. 
DNA extraction and qPCR: Genomic DNA from each T0 transgenic plant was isolated using a DNeasy Plant Mini Kit (Qiagen Sciences, Maryland, USA). Amplification reactions were carried out in a volume of $25 \mu \mathrm{L}$ containing $20-1 \mathrm{ng}$ of genomic DNA, $0.05 \mu \mathrm{M}$ of each forward and reverse primers and 1x Power SYBR Green PCR Master Mix (Applied Biosystems, Foster City, CA) using a 7500 Fast Real-Time PCR system (Applied Biosystems) and standard default thermal cycling conditions (initial step, $95^{\circ} \mathrm{C}$ for $10 \mathrm{~min}$ for polymerase activation, $\mathrm{PCR}$ (40 cycles), $95^{\circ} \mathrm{C}, 15 \mathrm{sec}$ for melting, $60^{\circ} \mathrm{C}, 1 \mathrm{~min}$ for annealing and extending, dissociation step set by the system software).

Oligonucleotide primers were designed using Primer Express, version 3 software (Applied Biosystems). To ensure maximum specificity and efficiency during quantitative PCR, primer pairs were further tested for linearity of response by constructing relative standard curves on six serial 2-fold dilutions. The templates used for the standard curve analysis were mixed genomic DNAs from all samples. The 7500 system software analyzed the SYBR fluorescence and produced standard curves by plotting the log concentration of the starting quantity against the threshold Cycle $(\mathrm{Ct})$. Data of a standard curve reported by the software includes slope, interception, correlation coefficients and Ct. For each primer set, standard curves were analyzed independently for at least three runs and standard curves repeatedly showing correlation coefficients of 0.99 or higher and PCR efficiencies (calculated by Efficiency $=\left[10^{(-1 / \text { slope })}\right]-1$ ) between 98 and 102\% were accepted. PCR product specificity was confirmed by melting-curve analysis and by electrophoresis on $4 \%$ agarose gel to ensure that PCR reactions were free of primer dimers and non- specific amplicons. Information on optimized primer pairs is listed in Table 1.

Transgene copy number calculation: A modified method (Weng et al., 2004) based on the equation of Livak and Schmittgen (2001) that does not require identical amplification efficiencies between PCR system for the target gene and internal control gene was used to calculate transgene copies. In brief, this method calculates copy numbers by obtaining the value of $\mathrm{X}_{0} / \mathrm{R}_{0}=10^{[(\mathrm{Ct}, \mathrm{X}-\mathrm{IX}) / \mathrm{SX}]-[(\mathrm{Ct}, \mathrm{R}-\mathrm{IR}) / \mathrm{SR}]}$ where $\mathrm{I}_{\mathrm{X}}$ and $\mathrm{I}_{\mathrm{R}}$ are intercepts of the standard curves of target and internal control genes, respectively, $S_{x}$ and $S_{R}$ are slopes of the standard curves of target and internal control genes, respectively and $\mathrm{Ct}, \mathrm{x}_{\mathrm{x}}$ and $\mathrm{Ct}_{\mathrm{R}}$ are the detected threshold cycles of amplification of the target and internal control genes to a tested sample and the values are reported by the 7500 system software. If the copy number of the internal control gene $\left(\mathrm{R}_{0}\right)$ is well defined, the copy number of the target gene $\left(\mathrm{X}_{0}\right)$ can easily be deduced from the $\mathrm{I}_{\mathrm{X}}, \mathrm{I}_{\mathrm{R}}, \mathrm{S}_{\mathrm{X}}, \mathrm{S}_{\mathrm{R}}, \mathrm{Ct} \mathrm{,}_{\mathrm{X}}$ and $\mathrm{Ct} \mathrm{t}_{\mathrm{R}}$ in the tested sample. The values from representative standard curves are listed in Table 2, including slopes $\left(\mathrm{S}_{\mathrm{X}}\right.$ and $\left.S_{R}\right)$ and intercepts $\left(I_{X}\right.$ and $\left.I_{R}\right)$ for the target genes, $\beta$ Glucuronidase (GUS) and hygromycin phosphotransferase II (hptII), (both genes are in Genbank accession number AF354045) and for the internal control gene LfKCS45 (a single copy endogenous gene encoding a root-specific 3-ketoacylCoA synthase, Genbank accession number AY695435 (Moon et al., 2004), correlation coefficients, PCR efficiencies and $\mathrm{Ct}$ range. For each plant DNA sample, triplicate sets of PCR reactions with primers of the hptII, gusA and LfKCS45 and duplicate negative controls (reaction samples without DNA templates), were prepared and run in a 96-well plate. The PCR experiments were repeated three times for each plate to ensure that similar results are obtained.

Table 1: Primers used in the qPCR assay

\begin{tabular}{|c|c|c|c|c|}
\hline \multirow{2}{*}{$\begin{array}{l}\text { Abbreviated } \\
\text { Gene Name }\end{array}$} & \multirow[b]{2}{*}{ GenBank ID } & \multicolumn{3}{|l|}{ Forward primer $\left(5^{\prime}-3^{\prime}\right)$} \\
\hline & & Reverse primer (5'-3') & Amplicon size (bp) & Position (bp) \\
\hline LfKCS45 & AY695435 & $\begin{array}{l}\text { CCAACTGCTTGTTCCGTCTTG } \\
\text { GTCTTCGTTCTCCCGACTTGTT }\end{array}$ & 66 & $1816-1881$ \\
\hline hptII & AF354045 & $\begin{array}{l}\text { CGCGTCTGCTGCTCCATAC } \\
\text { GGTCGCCAACATCTTCTTCTG }\end{array}$ & 57 & $9234-9290$ \\
\hline gusA & AF354045 & $\begin{array}{l}\text { ACAACGTCGTGACTGGGAAAA } \\
\text { TGTGCTGCAAGGCGATTAAG }\end{array}$ & 57 & $11108-11164$ \\
\hline
\end{tabular}

Table 2: Information of representative standard curves

\begin{tabular}{llllll}
\hline Gene name & Ct range & Slope & Interception & Correlation coefficients & PCR efficiencies \\
\hline LfKCS45 & $20-26$ & -3.3460 & 25.0723 & 0.9980 & 0.99 \\
hptII & $20-26$ & -3.3488 & 24.2839 & 0.9974 & 0.99 \\
gusA & $23-29$ & -3.2982 & 27.0508 & 0.9957 & 1.01 \\
\hline
\end{tabular}




\section{RESULTS}

As described ((Weng et al., 2004) Material and methods)), the transgene copy number was determined relative to an endogenous reference gene or internal control gene using qPCR technology. In this study, the first essential step was to obtain an endogenous sequence with confirmed low copy number per genome. A single-copy endogenous gene is the best choice for this analysis to ensure sensitivity of detection. We searched the NCBI database and identified a known single-copy endogenous gene, LfKCS45 encoding a root-specific 3-ketoacyl-CoA synthase (Moon et al., 2004) as the internal control. To ensure maximum specificity and efficiency during qPCR, we designed gene specific primers (Table 1) and validated the primers by optimizing primer concentrations and performing standard curves analysis (Material and methods). The 7500 system software produced standard curves by plotting the log concentration of the starting quantity against the threshold Cycle $(\mathrm{Ct})$ and also calculated the slope, interception and correlation coefficient for each standard curve.

Table 3: Ct values of 3 genes for each transgenic line from the qPCR assay

\begin{tabular}{llll}
\hline Sample & Ct $($ KCS45) & Ct $(\mathrm{hptII})$ & $\mathrm{Ct}($ gusA) \\
\hline 149 & $24.30 \pm 0.10$ & $24.64 \pm 0.11$ & $26.34 \pm 0.10$ \\
174 & $24.50 \pm 0.08$ & $24.65 \pm 0.06$ & $27.55 \pm 0.14$ \\
178 & $24.44 \pm 0.01$ & $24.66 \pm 0.07$ & $26.48 \pm 0.06$ \\
213 & $24.54 \pm 0.05$ & $24.70 \pm 0.05$ & $26.60 \pm 0.04$ \\
312 & $24.71 \pm 0.10$ & $25.00 \pm 0.05$ & $26.70 \pm 0.09$ \\
319 & $25.86 \pm 0.03$ & $24.61 \pm 0.01$ & $26.33 \pm 0.04$ \\
322 & $25.95 \pm 0.04$ & $24.61 \pm 0.09$ & $26.34 \pm 0.05$ \\
324 & $24.39 \pm 0.08$ & $24.61 \pm 0.02$ & $27.35 \pm 0.08$ \\
344 & $23.98 \pm 0.09$ & $24.22 \pm 0.03$ & $26.79 \pm 0.06$ \\
350 & $24.41 \pm 0.04$ & $23.69 \pm 0.06$ & $26.46 \pm 0.06$ \\
376 & $24.08 \pm 0.02$ & $23.26 \pm 0.02$ & $25.40 \pm 0.05$ \\
378 & $24.24 \pm 0.01$ & $23.40 \pm 0.10$ & $25.24 \pm 0.01$ \\
\hline Data are & &
\end{tabular}

Data are expressed as mean \pm SD of triplicate

Table 4: Estimated number of hptII and gusA copies for each line and possible rearrangements determined from the qPCR results

\begin{tabular}{|c|c|c|c|c|c|}
\hline \multirow[b]{2}{*}{ Sample } & \multicolumn{2}{|l|}{ hptII } & \multicolumn{2}{|l|}{ gusA } & \multirow[b]{2}{*}{ Rearrangement } \\
\hline & $\begin{array}{l}2 \text { times } \\
\left(\mathrm{X}_{0} / \mathrm{R}_{0}\right)\end{array}$ & $\begin{array}{l}\text { Number } \\
\text { of copies }\end{array}$ & $\begin{array}{l}2 \text { times } \\
\left(\mathrm{X}_{0} / \mathrm{R}_{0}\right)\end{array}$ & $\begin{array}{l}\text { Number of } \\
\text { copies }\end{array}$ & \\
\hline 149 & 0.92 & 1 & 1.93 & 2 & Yes \\
\hline 174 & 1.05 & 1 & 0.95 & 1 & No \\
\hline 178 & 1.00 & 1 & 1.93 & 2 & Yes \\
\hline 213 & 1.04 & 1 & 1.91 & 2 & Yes \\
\hline 312 & 0.95 & 1 & 2.00 & 2 & Yes \\
\hline 319 & 2.74 & $2-3$ & 5.68 & $5-6$ & Yes \\
\hline 322 & 2.92 & 3 & 6.00 & 6 & Yes \\
\hline 324 & 1.00 & 1 & 1.02 & 1 & No \\
\hline 344 & 0.99 & 1 & 1.13 & 1 & No \\
\hline 350 & 1.90 & 2 & 1.92 & 2 & No \\
\hline 376 & 2.04 & 2 & 3.21 & 3 & Yes \\
\hline 378 & 2.08 & 2 & 4.00 & 4 & Yes \\
\hline
\end{tabular}

Among the various PCR conditions tested, adjusting primer concentrations was the most effective way to optimize the PCR; low concentration of primers at 50 $\mathrm{nM}$ produced the best standard curves for each gene. The correlation coefficients of the standard curves of target genes, hptII and gusA and internal control gene LfKCS45 were very good (0.996-0.998, Table 2) and the PCR efficiencies were almost $100 \%$ (0.99-1.01, Table 2), indicating that all three genes had very similar reaction efficiencies over a range (2-64 fold) of initial DNA concentrations. Other information such as slopes and intercepts of the representative standard curves of hptII, gusA and LfKCS45 were also listed in Table 2. To estimate the transgene copy number, triplicate sets of PCR reactions were run for each DNA sample from T0 transformants; the reported $\mathrm{Ct}$ values were averaged over the triplicates and listed in Table 3. The standard deviations for the mean $\mathrm{Ct}$ values varied from 0.01-0.14 (Table 3), demonstrating low variability within replicates. Because the transgenic lines in the T0 generation are heterozygotes for the transgenes (hptII and gusA) and homozygotes for the endogenous gene (LfKCS45) (Mason et al., 2002), the numbers of copies of the target genes in T0 transformants should be calculated after the value of $\mathrm{X}_{0} / \mathrm{R}_{0}$ in equation, $\mathrm{X}_{0} / \mathrm{R}_{0}=$ $10^{[(\mathrm{Ct}, \mathrm{X}-\mathrm{IX}) / \mathrm{SX}]-[(\mathrm{Ct}, \mathrm{R}-\mathrm{IR}) / \mathrm{SR}]}$ is doubled (Weng et al., 2004). According to the equation, the number of transgene (hptII and gusA) copies of 12 T0 transformants were estimated (Table 4). For the hptII gene, 7 lines had 1 copy, 3 lines had 2 copies and the remaining 2 lines had about 3 copies. Comparison of the results of each sample (Table 4) indicated that the copy number of gusA gene was not entirely consistent with that of hptII, suggesting T-DNA rearrangements during the process of chromosomal integration. Of 12 tested samples, 8 $(149,178,213,312,319,322,376$ and 378) showed rearrangements (Table 4$)$.

\section{DISCUSSION}

We have developed a simple, rapid and effective qPCR method to estimate transgene copy number in transgenic L. fendleri. In this approach, the transgene copy is determined relative to an endogenous single copy gene, LfKCS4/5. Because the LfKCS $4 / 5$ sequence serves as an endogenous calibrator, it remains constant relative to the total genomic DNA of L. fendleri. Therefore, any variation in the relative level of the transgene to the endogenous gene is indicative of a difference in copy number. Also, the method incorporates the true amplification efficiencies of PCR systems in gene copy calculation, eliminating the need of having identical efficiencies between the PCR 
systems which is a prerequisite when using the original equation (Livak and Schmittgen, 2001) but sometimes is impractical or impossible to obtain (Weng et al., 2004). Among 12 transgenic plant samples, we found 8 samples having a low copy number (1 or 2$)$. This is consistent with the knowledge that Agrobacteriummediated transformation gives rise to lower copy numbers compared to direct transformation methods such as particle bombardment (Kohli et al., 2003). By using qPCR, we revealed T-DNA rearrangement events occurring in 8 out of 12 samples (66.7\%), i.e., because the hptII copy number did not agree with the gusA copy number. This $66.7 \%$ occurrence of rearrangement indicates that T-DNA rearrangements may be more common than generally thought. This discrepancy is likely associated with technique used, since the traditional Southern blotting technique examines only the transgene of interest, not the antibiotic selection gene and thus may not detect a large proportion of rearrangements. This qPCR method is more effective than Southern blot detection, as it allows simultaneous detection of the copy numbers of different genes and is more accurate in estimating transgene copy number. There is increasing evidence of T-DNA rearrangements in studies where qPCRs are utilized. For example, in tomato, of 15 transgenic lines investigated, at least 5 (i.e., 33.3\%) showed rearrangements (Mason et al., 2002). In rice, the estimated number of lines with rearrangements was high at $45.8 \%$, corresponding 11 of 24 evaluated lines (Yang et al., 2005). In rape seed (Weng et al., 2004) and cassava (Beltran et al., 2009), the number was $10 \%$ ( 2 of 20 ) and $13.3 \%$ ( 2 out of 15 ), respectively. The frequency of rearrangement may correlate to the host plant to be transformed and/or the transformation system, such as Agrobacterium strain, T-DNA vector and growth state of the Agrobacterium (Gelvin, 2003). In L. fendleri, we noted that the rearrangements showed more copies of the gusA gene than the hptII gene, indicating the T-DNA cassette must have undergone some kind of modification during the integration process in the plant genome. A T-DNA cassette consists of Right Border (RB), Left Border (LB) and genes of interests in between. The RB and LB delimit the T-DNA and are the only required ciselements that determine the T-DNA cassette integrating into plant genome. According to the main model of TDNA integration (Tzfira et al., 2004), T-DNA integration can be accompanied by some deletions in both ends; when they occur, deletions were more severe at the LB end (tail) compared with its RB end (head), because the RB is attached (or protected) by VirD2 protein which helps the integration. When two T-DNAs co-integrate to plant genome, T-DNAs can arrange to head-to-head or head-to-tail repeats prior to T-DNA integration. Tail-to-tail orientation occurs with less frequency. Moreover, large deletions (e.g., >1000 bp) occur particularly in one of the tails of the repeats at $100 \%$ frequency in head-to-head condition and at $21.6 \%$ in head-to-tail (Zhu et al., 2006). The T-DNA in pCAMBIA 1301.1 used in this study has the hptII gene located close to the LB (or tail) and the gusA close to the RB (head). A large deletion in the tail would truncate the T-DNA, resulting in loss of the hptII sequences and thus would be undetected by the qPCR method. Truncation of T-DNA may be a common phenomenon in rearranged T-DNAs in transgenic L. fendleri. Similar results were reported in rice (Afolabi et al., 2004), where truncation occured in $70 \%$ of the transgenes analyzed and $\sim 20 \%$ of them contained only a part of DNA, e.g., from the middle to RB. To gain an improved understanding of the mechanism of T-DNA rearrangement and integration, L. fendleri may serve as a suitable model species.

\section{CONCLUSION}

As described above, we have developed a qPCR method that can be implemented as a tool for rapid and accurate determination of transgene copy number in $L$. fendleri. Rearrangements are common during integration of two or more T-DNAs in the genome. When it occurs, the gene constructed next to the left border of T-DNA is likely to be truncated. Because the required sample size for the qPCR method is very small, the transgene copy number can be determined while T0 transgenics are still in the tissue culture stage. This allows the selection of desirable T0 plants and saves greenhouse space, which increases the capacity of the transgenic event production pipeline.

\section{ACKNOWLEDGMENT}

Researchers thank Colleen McMahan, Glenn Bartley, Kent McCue and Grisel Ponciano for critical reading of the manuscript. Thanks are extended to Dr. David Dierig for kindly supplying the $L$. fendleri seed. The work was supported by the United State Department of Agriculture, Agricultural Research Service, Current Research Information System (CRIS) Project 5325-2100-016-00D.

\section{REFERENCES}

Afolabi, A.S., B. Worland, J.W. Snape and P. Vain, 2004. A large-scale study of rice plants transformed with different T-DNAs provides new insights into locus composition and T-DNA linkage configurations. Theor. Applied Genet., 109: 815-826. DOI: $10.1007 / \mathrm{s} 00122-004-1692-y$ 
Beltran, J., H. Jaimes, M. Echeverry, Y. Ladino and D. Lopez et al., 2009. Quantitative analysis of transgenes in cassava plants using real-time PCR technology. In vitro Cellular Dev. Biol. Plant, 45: 48-56. DOI: $10.1007 / \mathrm{s} 11627-008-9159-5$

Caupin, H.J., 1997. Products from Castor Oil: Past, Present and Future. In: Lipid Technology and Application, Gunstone, F.D. and F.B. Padley (Eds.). Marcel Dekker, New York, ISBN: 10: 0824798384, pp: 787-795.

Costa, L.D., I. Vaccari, M. Mandolini and L. Martinelli, 2009. Elaboration of a Reliable strategy based on real-time PCR to characterize genetically modified plantlets and to evaluate the efficiency of a marker gene removal in grape (Vitis spp.). J. Agric. Food Chem., 57: 2668-2677. DOI: 10.1021/jf802740m

Dierig, D.A., A.M. Salywon, P.M. Tomasi, G.H. Dahlquist and T.A. Isbell, 2006. Variation of seed oil composition in parent and $\mathrm{S} 1$ generations of Lesquerella fendleri (Brassicaceae). Ind. Crops Prod., 24: 274-279. DOI: 10.1016/j.indcrop.2006.06.009

Dierig, D.A., P.M. Tomasi and G.H. Dahlquist, 2001. Registration of WCL-LY2 high oil Lesquerella fendleri germplasm. Crop Sci., 41: 604-605. DOI: 10.2135/cropsci2001.412604x

Dierig, D.A., P.M. Tomasi, A.M. Salywon and D.T. Ray, 2004. Improvement in hydroxy fatty acid seed oil content and other traits from interspecific hybrids of three Lesquerella species: Lesquerella fendleri, L. pallida and L. lindheimeri. Euphytica, 139: 199-206. DOI: 10.1007/s10681-004-3033-2

Doshi, K.M., F. Eudes, A. Laroche and D. Gaudet, 2007. Anthocyanin expression in marker free transgenic wheat and triticale embryos. In vitro Cellular Dev. Biol.-Plant, 43: 429-435. DOI: 10.1007/s11627-007-9089-7

Gelvin, S.B., 2003. Agrobacterium-mediated plant transformation: The biology behind the "genejockeying" tool. Microbiol. Mol. Biol. Rev., 67: 16-37. DOI: 10.1128/MMBR.67.1.16-37.2003

Ingham, D.J., S. Beer, S. Money and G. Hansen, 2001. Quantitative real-time PCR assay for determining transgene copy number in transformed plants. Biotechniques, 31: 132-140. PMID: 11464506

Isbell, T.A., M.S. Mund, R.L. Evangelista and D.A. Dierig, 2008. Method for analysis of fatty acid distribution and oil content on a single Lesquerella fendleri seed. Indus. Crops Prod., 28: 231-236. DOI: 10.1016/j.indcrop.2008.02.010
Jiang, L., L. Yang, H. Zhang, J. Guo and M. Mazzara et al., 2009. International collaborative study of the endogenous reference gene, Sucrose Phosphate Synthase (SPS), used for qualitative and quantitative analysis of genetically modified rice. J. Agric. Food Chem., 57: 3525-3532. DOI: 10.1021/jf803166p

Kohli, A., R.M. Twyman, R. Abranches, E. Wegel and E. Stoger et al., 2003. Transgene integration, organization and interaction in plants. Plant Mol. Biol., 52: 247-258. PMID: 12856933

Lazo, G.R., P.A. Stein and R.A. Ludwig, 1991. A DNA transformation-competent Arabidopsis genomic library in Agrobacterium. Nat. Biotechnol., 9: 963-967. DOI: $10.1038 /$ nbt1091-963

Li, Z., J.L. Hansen, Y. Liu, R.S. Zemetra and P.H. Berger, 2004. Using real-time PCR to determine transgene copy number in wheat. Plant Molecular Biol. Reporter, 22: 179-188. DOI: 10.1007/BF02772725

Livak, K.J. and T.D. Schmittgen, 2001. Analysis of relative gene expression data using real-time quantitative PCR and the 2(-Delta Delta C(T)) method. Methods, 25: 402-408. PMID: 11846609

Mason, G., P. Provero, A.M. Vaira and G.P. Accotto, 2002. Estimating the number of integrations in transformed plants by quantitative real-time PCR. BMC Biotechnol., 2: 20-20. PMID: 12398792

Moon, H., G. Chowrira, O. Rowland, B.J. Blacklock and M.A. Smith et al., 2004. A root-specific condensing enzyme from Lesquerella fendleri that elongates very-long-chain saturated fatty acids. Plant Mol. Biol., 56: 917-927. DOI: 10.1007/s11103-004-6235-z

Murashige, T. and F. Skoog, 1962. A revised medium for rapid growth and bioassays with tobacco tissue cultures. Physiol. Plant, 15: 473-497. DOI: 10.1111/j.1399-3054.1962.tb08052.x

Omar, A.A., M.G.H. Dekkers, J.H. Graham and J.W. Grosser, 2008. Estimation of transgene copy number in transformed citrus plants by quantitative multiplex real-time PCR. Biotechnol. Prog., 24: 1241-1248. DOI: 10.1002/btpr.62

Schmidt, M. and W. Parrott, 2001. Quantitative detection of transgenes in soybean [Glycine max (L.) Merrill] and peanut (Arachis hypogaea L.) by real-time polymerase chain reaction. Plant Cell Rep., 20: 422-428. DOI: 10.1007/s002990100326

Shou, H., B.R. Frame, S.A. Whitham and K. Wang, 2004. Assessment of transgenic maize events produced by particle bombardment or Agrobacterium-mediated transformation. Molecular Breed., 13: 201-208. DOI: 10.1023/B:MOLB.0000018767.64586.53 
Skarjinskaia, M., Z. Svab and P. Maliga, 2003. Plastid transformation in Lesquerella fendleri, an oilseed Brassicacea. Trans. Res., 12: 115-122. DOI: 10.1023/A:1022110402302

Song, P., C. Cai, M. Skokut, B. Kosegi and J. Petolino, 2002. Quantitative real-time PCR as a screening tool for estimating transgene copy number in WHISKERS $^{\mathrm{TM}}$-derived transgenic maize. Plant Cell Rep., 20: 948-954. DOI: 10.1007/s00299-0010432-X

Subr, Z., S. Novakova and H. Drahovska, 2006. Detection of transgene copy number by analysis of the $\mathrm{T} 1$ generation of tobacco plants with introduced P3 gene of potato virus A. Acta Virol., 50: 135-138. PMID: 16808332

Tzfira, T., J. Li, B. Lacroix and V. Citovsky, 2004. Agrobacterium T-DNA integration: Molecules and models. Trends Genet., 20: 375-383. DOI: 10.1016/j.tig.2004.06.004

Wang, W., C. Wang, B.L. Huang and B. Huang, 2008. Agrobacterium tumefaciens-mediated transformation of Lesquerella fendleri L., a potential new oil crop with rich lesquerolic acid. Plant Cell, Tissue Org. Cult., 92: 165-171. DOI: 10.1007/s1 1240-007-9319-z
Weng, H., A. Pan, L. Yang, C. Zhang and Z. Liu et al., 2004. Estimating number of transgene copies in transgenic rapeseed by real-time PCR assay with HMG I/Y as an endogenous reference gene. Plant Mol. Biol. Rep., 22: 289-300. http://pubs.nrccnrc.gc.ca/ispmb/r04-049.html

Yang, L., J. Ding, C. Zhang, J. Jia and H. Weng et al., 2005. Estimating the copy number of transgenes in transformed rice by real-time quantitative PCR. Plant Cell Rep., 23: 759-763. DOI: 10.1007/s00299-004-0881-0

Yi, C.X., J. Zhang, K.M. Chan, X.K. Liu and Y. Hong, 2008. Quantitative real-time PCR assay to detect transgene copy number in cotton (Gossypium hirsutum). Anal. Biochem., 375: 150-152. DOI: 10.1016/j.ab.2007.11.022

Zhu, Q.H., K. Ramm, A.L. Eamens, E.S. Dennis and N.M. Upadhyaya, 2006. Transgene structures suggest that multiple mechanisms are involved in T-DNA integration in plants. Plant Sci., 171: 308-322. DOI: 10.1016/j.plantsci.2006.03.019 